Boise State University

ScholarWorks

Educational Technology Faculty Publications and

Presentations

Department of Educational Technology

2-1-2011

The Development of a Content Analysis Model for Assessing Students' Cognitive Learning in Asynchronous Online Discussions

Dazhi Yang

Boise State University

Jennifer C. Richardson

Purdue University

Brian F. French

Washington State University

James D. Lehman

Purdue University

This is an author-produced, peer-reviewed version of this article. The final publication is available at www.springerlink.com. Copyright restrictions may apply. DOI: 10.1007/s11423-010-9166-1 


\title{
The Development of a Content Analysis Model for Assessing Students' Cognitive Learning in Asynchronous Online Discussions
}

\author{
Dazhi Yang \\ Boise State University, Boise, ID \\ Jennifer C. Richardson \\ Purdue University
}

\author{
Brian F. French \\ Washington State University \\ James D. Lehman \\ Purdue University
}

\begin{abstract}
The purpose of this study was to develop and validate a content analysis model for assessing students' cognitive learning in asynchronous online discussions. It adopted a fully mixed methods design, in which qualitative and quantitative methods were employed sequentially for data analysis and interpretation. Specifically, the design was a "sequential exploratory" (QUAL $\rightarrow$ quan) design with priority given to qualitative data and methods. Qualitative data were 800 online postings collected in two online courses. Quantitative data were 803 online postings from the same two courses but from different discussion topics and different weeks. During the qualitative process, a grounded theory approach was adopted to construct a content analysis model based on qualitative data. During the quantitative process, chi-square tests and confirmative factor analysis (CFA) which used online postings as cases or observations and was the first of its kind were performed to test if the new model fit the quantitative data.
\end{abstract}

Keywords: content analysis, assessment, asynchronous online discussions, cognitive learning, mixed methods

\section{Introduction}

Online and distance learning has exploded and the enrollment in online courses continues to grow (Allen and Seaman 2008). With the prevalence of online learning, the assessment of students' learning outcomes, defined as the obtained knowledge, skills, and abilities (CHEA 2002), is attracting attention in several areas (Anderson 2008; Garrison 2003). The assessment of online and distance learning is of a particular concern both because of historical issues of quality raised about distance education (Reeves 2000; Savenye 2004) as well as issues such as the lack of meaningful assessment (Moallem 2005) and the time-consuming nature of assessment in distance and online courses (Savenye 2004).

Asynchronous online discussions (AODs) are a common pedagogical practice in online courses (McLoughlin and Luca 2000; Swan, Schenker, Arnold and Kuo 2007). AODs, when used effectively, provide a catalyst for the teaching of and facilitating critical thinking skills in students (Yang 2008). Assessment of students' learning in AODs is not only necessary but also can shape the quality of discussions (Swan et. al. 2007). Researchers suggest that online instructors should assess AODs for the quality not the quantity of student participation (Henri 1992; Swan, Shen and Hiltz 2006). Furthermore, the assessment of AODs should focus on the cognitive aspect of students' learning outcomes as this is the ultimate goal of the education process (Garrison, 2003).

Although the assessment of AODs is critical, assessing students' cognitive learning is one of the most challenging tasks in online learning. This is mainly due to: 1) a lack of knowledge about assessing students' cognitive learning outcomes in such an environment (Mazur 2004); and 2) challenges for online instructors to create assessment instruments or grading rubrics on their own (Wijekumar, Ferguson and Wagoner 2006). If instructors who teach online are facing challenges and are poorly-equipped to assess students' cognitive learning in AODs, it is difficult for them to measure and interpret students' learning outcomes and performance in a timely and accurate matter. This affects online instructors' abilities to provide effective feedback and adapt instructional strategies accordingly. 


\section{Literature Review}

\section{Content Analysis of Asynchronous Online Discussions}

In the past, most assessment approaches related to AODs were based on quantity rather than the quality of postings (Marra, Moore and Klimczak 2004). A little more than a decade ago, a shift occurred from a focus on quantity to a focus on quality. One of the most appropriate ways to assess AOD quality is content analysis (Henri 1992). Content analysis breaks online postings into units, which are sets of the to-be analyzed material (e.g., text, images, voices), then categorizes the units and counts "the number of units in each category" (Corich, Kinshuk and Hunt 2006, p. 2).

A content analysis model for AODs analyzes students' online discussions and assesses students' learning revealed in AODs. The need for a content analysis model specifically developed for AODs was well discussed more than a decade ago. Introducing the different social and interactive dimensions of computer-mediated conferencing (CMC), Henri (1992) argued the assessment of AODs is unique and different from that of the assessment of classroom discussions and traditional discourse analysis. More recently, discussions of the integration of cognitive (reflection and discourse), social (personal and emotional connection), and teaching presence (structured process) elements in AODs further contributed to the argument (Garrison, Anderson and Archer 2000; Garrison 2003). However, assessing students' cognitive learning in AODs is not without challenges. The challenges mainly stem from the complexity of online learning environments in terms of different kinds of interactions (Henri 1992), the lack of appropriate and effective content analysis models (Mazur 2004), and the instructors' lack of knowledge about how to create assessment rubrics for AODs (Reeves, 2000).

There are several content analysis models available for assessing AODs that have frequently been adopted and cited. These include (1) Henri's (1992) Cognitive Framework, (2) Newman, Webb, and Cochrane's (1996) Critical Thinking Content Analysis Framework, (3) Gunawardena, Lowe and Anderson's (1997) Interaction Analysis Model (IAM), and (4) Garrison, Anderson, and Archer's (2001) Critical Thinking and Cognitive Presence Model, which were all specifically created for assessing AOD postings. According to Google Scholar, Henri (1992) has been cited 824 times, Gunawardena et al. (1997) have been cited 657 times, Garrison et al. (2001) have been cited 506 times, and Newman et al. (1996) have been cited 114 times as of April, 2010.

Before discussing each model, it is necessary to discuss the cognitive domain of Henri's (1992) Cognitive Framework and Garrison's (1992) Critical Thinking Model because they served as the theoretical foundation for other models. The cognitive aspect of Henri's Framework (see Table 1) corresponds to the cognitive domain of Bloom's (1956) Taxonomy, specifically at the analysis, synthesis, and evaluation levels. Although related to Bloom's Taxonomy, Henri's (1992) Framework focuses on reasoning skills and highlights the cognitive learning processes that can be found in online postings. The indicators of reasoning skills demonstrate the learning processes of higher-order thinking.

Table 1 Reasoning Skills of in Henri's (1992) Cognitive Framework

\begin{tabular}{ll}
\hline Reasoning Skills & \multicolumn{1}{c}{ Indicators } \\
\hline Elementary clarification & $\begin{array}{l}\text { Identifying relevant elements; } \\
\text { Reformulating the problem; } \\
\text { Asking a relevant question; } \\
\text { Identifying previously stated hypotheses. }\end{array}$ \\
& $\begin{array}{l}\text { Defining the terms; } \\
\text { Identifying assumptions; } \\
\text { Establishing referential criteria; } \\
\text { Seeking out specialized information. }\end{array}$ \\
& Drawing conclusions; \\
& Making generalizations; \\
& Formulating a proposition which proceeds from previous statement.
\end{tabular}




\begin{tabular}{ll}
\hline Judgment & $\begin{array}{l}\text { Judging the relevance of solutions; } \\
\text { Making value judgments; } \\
\text { Judging inferences. }\end{array}$ \\
\hline Strategies & $\begin{array}{l}\text { Deciding on the action to be taken; } \\
\text { Proposing one or more solutions; } \\
\text { Interacting with those concerned. }\end{array}$ \\
\hline
\end{tabular}

Critical thinking relates closely to higher-order thinking, specifically, reasoning and problem-solving. There are numerous definitions of critical thinking (Facione, Facione and Giancarlo 2000; Facione, Giancarlo, Facione and Gainen 1995; Garrison 1992). However, the essence of critical thinking is reflective and purposive judgment(s) (Facione et al. 2000). Thinking and reflection may be purposeful but not necessarily critical in nature. Critical thinking involves "skepticism, argument or suspension" toward a "statement, established norm or mode of doing things" (McPeck 1981, p. 6), which makes critical thinking a form of higher-order thinking. In his critical thinking model, Garrison (1992) defined critical thinking as a five-stage problem-solving process. These problem-solving stages and critical thinking skills in Garrison's Critical Thinking Model (1992) are closely related to the cognitive skills in Henri’s (1992) Cognitive Framework.

Stage 1. Problem identification: Learners observe or study a problem, identify its elements, and observe their linkages to come to a basic understanding.

Stage 2. Problem definition: Learners analyze a problem to come to an understanding which sheds light on the values, beliefs and assumptions which underlie the statement of the problem.

Stage 3. Problem exploration: Learners admit or propose an idea on the basis of its link with propositions already admitted as true through induction and deduction.

Stage 4. Problem applicability: Learners evaluate alternative solutions and new ideas within a social context.

Stage 5. Problem integration: Learners propose coordinated actions for the application of a solution, or follow through on a choice or decision.

Based on Henri's (1992) reasoning skills and Garrison's (1992) model of critical thinking, Newman et al. (1996) developed an analytical framework for studying critical thinking, which consists of a list of critical thinking indicators. Since there are more than forty indicators, reliability is a major issue due to the potential for crosscoding and or overlooking codes in the process of application (Marra 2006). Given the concern with its reliability, the validity of the model is questionable. In addition, it is difficult to interpret content analysis results generated from Newman et al.'s framework in a meaningful way because it assigns critical ratios ranging from 1 to +1 to a sentence or phrase in a posting (Marra et al. 2004). From an assessment perspective, these critical ratios $(-1$ to +1$)$ are hard to interpret. Thus, Newman et al.'s framework is more suitable for the purpose of research.

Garrison et al. (2001) also developed a content analysis model based on Henri's (1992) and Garrison's (1992) work. This model has four phases: 1) triggering events (recognizing the problem), 2) exploration (divergence within groups and a message, information exchanges, suggestions, brainstorming, and leaps to conclusions), 3) integration (convergence among groups and within a message, connecting ideas and creating solutions), and 4) resolution (vicarious application to real world, testing and defending solutions). Both the Newman et al. and Garrison et al. models focus on higher-order thinking skills and the learning processes by which critical thinking skills are demonstrated through different steps of the problem-solving and reasoning. However, AODs do not always involve problem-solving or require students to respond at the highest levels of critical thinking.

Gunawardena et al.'s (1997) IAM was designed to assess the process of social knowledge construction and collaborative learning. The IAM consists of five phases of knowledge construction. Phase I is the sharing or comparing of information. Phase II is the discovery and exploration of dissonance or inconsistency. Phase III is the negotiation of meaning or co-construction of knowledge. Phase IV is the testing and modification of proposed synthesis or co-construction. Finally, Phase V is agreement statements or applications of newlyconstructed meaning. The IAM provides an assessment of the process of and the relationship between interaction (exchanges and dialogues) and knowledge construction.

From the perspective of online learning and interaction, the IAM focuses on social interaction (student-tostudent and student-to-instructor) and social knowledge construction. It does not address student-to-content interaction (Moore 1989), which is similar to what Barbera (2006) called the "preliminary phase" (reading 
content materials and preparing for the discussion) of AODs. This takes place before the "interactive phase" and "concluding phase" (Barbera 2006) and may have more indicators of knowledge acquisition and lower levels of cognitive skills because it represents students' initial understandings of the content.

All four models can be considered problematic when considering the kind of learning (knowledge and or skills) each aims to measure, the intention and focus of each model, and the context in which each was developed. In a review of 19 studies of content analysis models or frameworks that included those for measuring participation and social dimension of CMC, Rourke, Anderson, Garrison, and Archer (2001b) concluded that the main shortcoming of those models or frameworks is validity. Of the 19 studies, only 10 reported reliability data. Therefore, an effective (valid and reliable) and a complete (measuring all levels of cognitive learning) content analysis model is needed for measuring student's learning in AODs.

\section{Research Questions}

In response to the different foci and weakness of the major AOD models, this study sought to develop a content analysis model that includes indicators of knowledge acquisition and all levels of cognitive skills. A general assessment tool for cognitive skills and knowledge is the revised Bloom's Taxonomy (Anderson and Krathwohl 2001), which has a two-dimensional structure with knowledge separated from cognitive processes (skills) in the cognitive domain. The knowledge dimension consists of Factual, Conceptual, Procedural, and Meta-Cognitive Knowledge. The cognitive process dimension consists of six levels of cognitive phases (Anderson and Krathwohl 2001, p. 67-68).

1. Remembering: Retrieving, recognizing, and recalling relevant knowledge.

2. Understanding: Constructing meaning from oral, written, and graphic messages.

3. Applying: Carrying out or using a procedure through executing, or implementing.

4. Analyzing: Breaking material into constituent parts, determining how the parts relate to one another and to an overall structure or purpose.

5. Evaluating: Making judgments based on criteria and standards.

6. Creating: Putting elements together to form a coherent or functional whole; reorganizing elements into a new pattern or structure.

However, some of the indicators of the above six cognitive phases, such as retrieving and recalling relevant knowledge in Remembering, are not applicable for assessing AODs because students have different resources readily available when composing online postings. Thus, the overarching research question of this study was: How can online instructors fairly and effectively assess students' cognitive learning in asynchronous online discussion? Specific research questions were as follows:

1) What are the components, in terms of knowledge acquisition and cognitive skills, of a content analysis model that can help an instructor assess students' cognitive learning in asynchronous online discussions (AODs)?

2) Do the data collected from two distance courses, which have knowledge acquisition and cognitive skills as their main learning objectives, fit or support the content analysis model?

Knowledge acquisition in this study was defined as learned "new and contextual information" (Armour-Thomas 1986). It can be categorized into factual, conceptual, and procedural knowledge (Anderson and Krathwohl 2001). Knowledge acquisition is domain specific and is closely related to the subject and content. Cognitive skills were defined as the intellectual or mental activities that process information and stimuli (CAASG 2006), such as perceiving and remembering new information. The cognitive component (of cognitive skills) is reflected in knowing something and the skills component (of cognitive skills) is reflected in exhibiting of the knowing (Schumacher, West and Angell 1997). Cognitive skills encompass knowledge but are beyond knowledge. Cognitive skills can be categorized into sharing or comparing information (Gunawardena et al. 1997), applying, and analyzing (Bloom 1956).

We do note that there are several levels of model development with each level addressing essentially a different step in validation research to support the model and more importantly the inferences that may be drawn from the model. At the basic level, these models begin as descriptive models and describe the construct of interest at the content level. For instance, the descriptive model is judged, in part, by experts in the area to accurately and fully capture the abilities assessed (e.g., student learning in a given domain). The next level of models we begin to address was predictive in nature. Statistical methods, such as confirmatory factor analysis, allowed us to test the descriptive models to examine if our constructs account for or predict responses on the identified indicators. 
This provided internal structure validity evidence of the model (Kane, 2006). The descriptive versus predictive aspects were the first and second foci, respectively, of the current study. The current study did not focus on the decision and inference aspects of models.

In summary, the purpose of this study was to develop, validate, and test a content analysis model for assessing knowledge acquisition and cognitive skills (students' cognitive learning) in AODs. The study adopted a fully mixed methods design, in which qualitative and quantitative methods were employed sequentially (Hanson, Creswell, Plano-Clark, Petska and Creswell 2005). The expected outcome of the study was an effective (valid and reliable) and a complete (measuring all levels of cognitive learning) content analysis model for measuring student's learning in AODs.

\section{Methods}

\section{Context and Participants}

The context of the study was two online courses (1) Foundations of Distance Education (FDE) and (2) Integration and Management of Computers in Education (IMCE) offered at a large Midwestern university in the United States. Both courses were three-credit, graduate-level courses, and had acquisition of knowledge and cognitive skills as major learning objectives. Both courses were primarily delivered via WebCT (now Blackboard) Vista following an initial face-to-face meeting. Asynchronous online discussion was the main instructional method in both courses. Carefully designed discussion topics and prompts (see sample discussion questions and topics in Appendix A) were assigned to students each week.

All students were required to post at least two to three messages during one week, with an initial response to the discussion question(s) and at least one to two responses to peers' postings. On average there were 5.5 postings per student per discussion with a range of 71-115 postings for the FDE course and a range of 59-87 postings for the IMCE course thereby providing a rich amount of postings for inclusion within the study. Students' online postings were graded and accounted for $30 \%$ of the final grade in the IMCE course and 35\% in the FDE course. The weekly online discussions in both courses were moderated and facilitated by the course professor and a teaching assistant and lasted for 15 weeks. Facilitation of the discussions, for both courses, included the instructor's "interacting" a minimum of three times per week in each discussion with additional posts made by the teaching assistant. Interactions included prompting for further information, providing examples, describing potential consequences or implications, playing the role of devil's advocate, posing clarifying questions, and suggesting a different perspective or interpretation. The 15-week online discussions provided a variety of student postings and also could be considered a positive aspect over other content analysis model studies which were based on only several weeks' AODs. Analyses of students' online discussion postings in this context should reflect students' efforts and their learning.

Both courses attracted students $(N=31)$ from various schools and colleges, including education, science, and technology. The IMCE course had 18 students and the FDE had 13 students. Students' ages ranged from 21 to 40 plus years old. Students were from mixed ethnicities and included both traditional and non-traditional students. Participants had different levels of experience with asynchronous CMC and online courses. All enrolled students' online postings were initially included in the study, but postings that did not address the course content, such as compliments and greetings, were removed from the study.

\section{Research Design}

The study adopted a fully mixed methods design, in which qualitative and quantitative methods were employed sequentially at stages of data analysis and data interpretation (Hanson et al. 2005). Specifically, the design was a "sequential exploratory" (QUAL $\rightarrow$ quan) mixed methods design with priority given to the qualitative data and methods. Quantitative data, which were the data used in the quantitative method, supplemented the qualitative data, which were the data used in the qualitative method. A sequential exploratory design is useful for exploring relationships, "refining and testing an emerging theory" "based on an initial qualitative analysis" (Hanson et al. 2005 , p. 229). Thus, the study was conducted in two processes: qualitative methods were used to develop the content analysis model - the qualitative process, and then quantitative methods were used to provide empirical support for the newly developed model - the quantitative process. Each of the two processes served its own unique purpose.

The qualitative data consisted of 800 online postings generated by discussion topics selected in weeks $2,4,6,8$, 10,12 , and 14 from both courses and were used to address the first research question. The quantitative data consisted of 803 online postings generated by discussion topics selected from weeks 3, 5, 7, 9, 11, 13, and 15 
from both courses and were used to address the second research question. Since the two sets of data were generated from different weeks and from different discussion questions, they were considered to be different but similar allowing for the use of one sample for development of the model and a second sample as a way to test it. Realizing that discussion question formats varied across weeks (see Appendix A), we grouped the online postings into two sets comprised of postings from every other week in the attempt to make the two sets of data comparable, each of which provided similar opportunities for students to demonstrate cognitive learning.

\section{Content Validity}

Prior to the development of a content analysis model, three online learning experts, who had at least five-year of classroom teaching experience and taught at least one online course, reviewed all discussion topics regarding their inclusions in the study for the purpose of content validity. Content validity is the degree to which a test or an instrument measures what it is supposed to measure (Brown, 1996). Evidence of content validity is often well-trained experts' judgments about the degree to which a test or an instrument matches the assessment objective(s) or specifications. Three experts independently reviewed 30 discussion questions and topics (18 from course IMCE and 12 from course FDE) across the two courses along with detailed course objectives and syllabi. Three experts then indicated whether a discussion topic truly reflected the course major learning objective(s) (either knowledge acquisition or cognitive skills). Only those topics $(n=22)$ that reflected the courses' main learning objectives and were selected by at least two experts were included in the study. The experts' reviews ensured the selected discussion topics were valid (measuring what it is supposed to measure), which was critical to develop a valid content analysis model (Moskal \& Jon, 2000). The expert reviews also ensured a rigorous process of data collection, i.e., only appropriate online postings generated by valid discussion topics were included in the study.

\section{Qualitative Methods}

During the qualitative process (Fig. 1), a grounded theory (Glaser and Strauss 1967) approach was adopted to find the components of a content analysis model, in terms of knowledge acquisition and cognitive skills, for assessing students' cognitive learning in AODs. Grounded theory has five analytic phases (Pandit 1996). Since the data were previously collected, this study adopted two phases: the data analysis and literature comparison. The unit of analysis was at the posting level, which "correspond[ed] to what one participant posted into one thread of the discussion on one occasion" (Garrison, Anderson, and Archer 2001, p. 9). We chose the unit of analysis at the posting level because online instructors usually assign points based on individual postings.

During the data analysis phase (coding the 800 online postings), both percentage agreement (Miles and Huberman 1994) and Cohen's Kappa that takes into count chance agreement were computed for the purpose of inter-coder reliability checks. The initial inter-coder reliability agreement based on 160 online postings between two coders was $71 \%$. The final percentage agreement after coming to consensus through face-to-face discussions between the two coders was $97 \%$. The Cohen's Kappa was .98 and indicated a very strong level of agreement between the two coders. During the literature comparison phase, we compared our coding scheme with the four major existing content analysis models or frameworks (discussed in the literature review) and revised our coding scheme accordingly. The literature comparison identified the similarities and differences between our coding scheme and the existing models or frameworks. It enhanced the validity and reliability of the newly developed model (the initial model) in terms of the references it generated (Pandit 1996).

After the literature comparison, another three online experts who had both taken and taught online courses reviewed the initial model. The purpose of the experts' reviews was to collect feedback and suggestions from them on the categories, sub-categories, and propositions (grouping) of the categories. The review also invited the experts' opinions on how easy or difficult it was to use the new model for assessing students' cognitive learning in AODs. Furthermore, the experts' reviews were intended to check the content validity of the new model regarding whether the categories and sub-categories were representative of the constructs (knowledge and cognitive skills) (Anderson n.d.). 


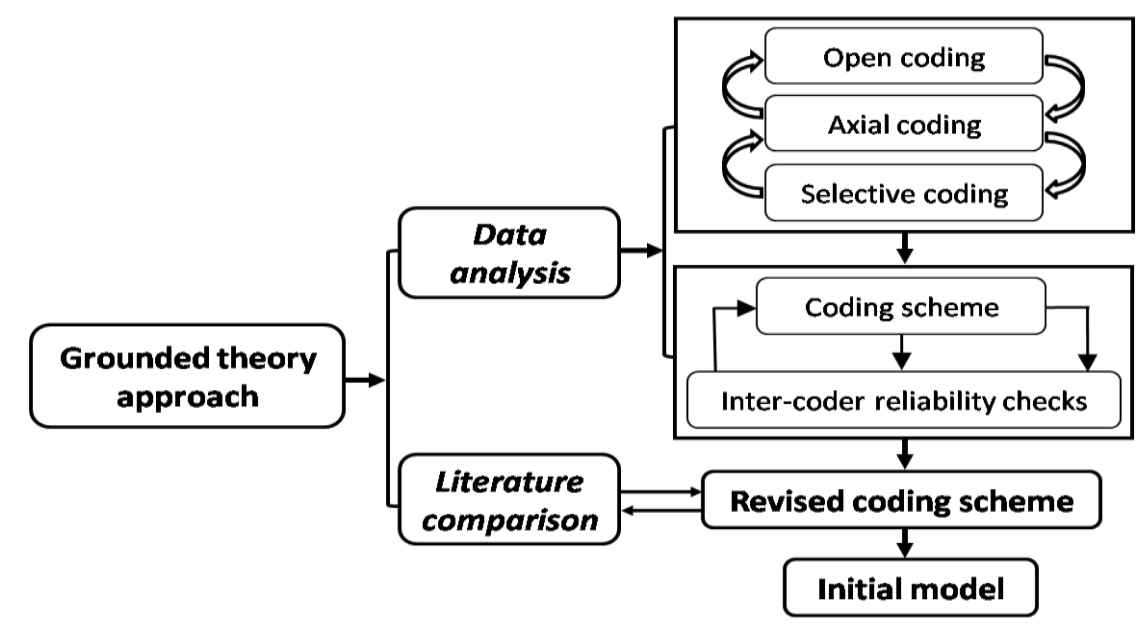

Fig. 1. The Qualitative Process

\section{Quantitative Method}

Each of the online posting in the quantitative data $(N=803)$ was coded 1 if a sub-category of learning in the initial model was revealed and 0 if it was not. Then the frequency count and proportion of each sub-category for every posting were calculated. Similarly, the frequency counts of the qualitative data $(N=800)$ were also generated. Chi-square tests were then conducted to compare the frequency counts of both sets of data, allowing the researchers to check whether all categories and sub-categories in the initial model equally appeared in the quantitative data (Pallant 2007). If there is a significant chi-square value $(\mathrm{p}<0.05)$, the corresponding subcategory would have appeared less frequently in the quantitative data set, which corresponded to having a smaller proportion. If the sub-categories did not appear in the quantitative data as often as they did in the qualitative data, they were removed from the initial model or regrouped into the next sub-category according to the "code up (i.e., to the later phase)" rule suggested by Garrison, Anderson, and Archer (2001). The excluding and regrouping of some of the categories and sub-categories in the initial content analysis model yielded a modified model with fewer sub-categories.

A confirmative factor analysis (CFA) was conducted to further address the second research question "Do the data collected from two distance courses, which have knowledge acquisition and cognitive skills as their main learning objectives, fit or support the content analysis model?". The purpose of the CFA was to determine the ability of the initial model to fit a new sample of online postings, the quantitative data (DeCoster 1998). Since the initial model was developed based on the qualitative data, the model was hypothesized to fit the quantitative data from the same two courses. Statistically speaking, CFA is a measurement model that depicts the relationships between the observed variables or indicators and the latent variables or factors (Joreskog and Sorbom 2001). The indicators here were the sub-categories of knowledge and cognitive skills and the factors were categories of knowledge and cognitive skills. The data inputs for the observed variables or indicators were the frequency count of each sub-category of cognitive learning in every posting $(N=803)$. The CFA was conducted using LISREL 8.3 (Scientific Software International 2007). The maximum likelihood estimation method was used. Five model fit indexes, the chi-square significance test, root mean square error of approximation (RMSEA), goodness of fit (GFI) and adjusted goodness of fit (AGFI), and comparative fit index (CFI) were evaluated. The use of multiple fit criteria follows recommendations to examine combinations of fit indexes (Hu and Bentler 1999).

\section{Results}

\section{Qualitative Results: The Initial Content Analysis Model}

The components of students' cognitive learning revealed in AODs were identified as categories and subcategories of knowledge acquisition and cognitive skills. Thus, the initial model has a two-dimensional structure: knowledge and cognitive skills. Specifically, there are three categories (levels) of knowledge: 1) Factual Knowledge (FK), 2) Conceptual Knowledge (CK), and 3) Procedural Knowledge (PK). There are five categories (levels) of cognitive skills: 1) Sharing/Describing/Seeking information or solutions (CS-SDS), 2) Explaining/Comparing/Interpreting/Clarifying (CS-ECIC), 3) Analyzing/Concluding (CS-AC), 4) Applying 
(CS-A), and 5) Creating (CS-C). In addition, each category has respective sub-categories. The model being developed also provides explanations of the different levels of categories and sub-categories (see Table 2) as a guideline for online instructors and adopters.

It should be noted that most knowledge sub-categories were associated with short phrases or words, such as learning management systems (LMSs) (FK-DT) and Angel (FK-DT) in the following posting:

I think that often students can use technology in team building situations. Many kinds of learning management systems feature message boards and contained email like WebCT does. The one that I am most familiar with is called Angel ...

However, sentences or paragraphs where knowledge sub-categories appeared could also be coded with cognitive skills sub-categories. For example, the posting cited above could also be coded as CS-ECIC-PSPR (personal learning experience) because the student wrote his or her perspective and supported it with a personal example.

Postings could also be cross-coded for multiple sub-categories. For example, the following posting not only provided new information (FK-NI) but also described what was available at the URL (CS-SDS-DCS). Thus, it could be cross-coded with both FK-NI (knowledge) and CS-SDS-DCS (cognitive skills).

I managed to track down the assistant software/hardware available to students with special needs. You can take a look at what they have here: http://www.itap.purdue.edu/tlt/idc/alps/labinfo.cfm. From the looks of it, it's pretty much limited to students with visual or audio-related needs. ...it was interesting that they not only provided Braille technology to be used with a computer, but they have an embosser for printing Braille documents as well.

More examples for each initial code are provided in Appendix B.

\section{Quantitative Results}

The proportions of six sub-categories of learning (K-NI, CK-GPR, CK-CC, CS-ECIC-CDI, CS-AC-CB, and CS-AC-AER in Table 2) in the initial model were less than $10 \%$ in both qualitative and quantitative data. Due to the small proportions of these sub-categories, a decision was made to collapse each sub-category into a higher category or regroup it with similar sub-categories to facilitate further quantitative analysis. For example, the sub-category K-NI was regrouped with a similar sub-category (FK-O) due to its small proportions (6\% in qualitative data and $7.97 \%$ in the quantitative data) and was renamed as FK-ON.

The occurrences of each sub-category from the coding of qualitative data and quantitative data also were obtained, which were compared to see if a sub-category appeared in both sets of data. For the chi-square tests, the $p$ values of 11 sub-categories of learning were larger than .05 (see Table 3), which indicated that there were no significant differences between the occurrences of these 11 sub-categories in both sets of data. There were six sub-categories that did show significant differences $(p<0.05)$. However, among these six sub-categories, four sub-categories (K-NI, PK-EC, CS-ECIC-PSPR, and CS-ECIC-CDI) had a larger observed frequency (in quantitative data) than the minimum expected frequency (in qualitative data), which indicated that they appeared more frequently in the quantitative data. Only two of these sub-categories (CK-TM and CS-ECIC-PE) had a smaller observed frequency than the minimum expected frequency, which indicated that they did not appear as frequently in the quantitative data as they appeared in the qualitative data. Consequently, CK-TM and CS-ECIC$\mathrm{PE}$ had to be excluded or regrouped. However, the small observed frequency of some sub-categories according to the initial model might either be a coding issue or merely a function of the topics discussed in the two online courses, which were two possible limitations of this study. 


\section{Table 2 The Content Analysis Model Being Developed}

\begin{tabular}{|c|c|c|}
\hline Code & Category and Sub-category & Explanations \\
\hline$K$ & - Knowledge & Knowledge is the new and contextual (content related) information. \\
\hline FK & ○ Factual Knowledge & $\begin{array}{l}\text { Factual knowledge is defined as "the basic elements" one has to know to be familiar with a } \\
\text { discipline or to "solve problems in it." }\end{array}$ \\
\hline FK-DT & $\begin{array}{ll}\text { - } & \text { Definitions } \\
\text { - } & \text { Terminologies }\end{array}$ & Definitions and terminologies of a discipline or field. \\
\hline $\mathrm{K}-\mathrm{NI}$ & - New knowledge or information & $\begin{array}{l}\text { Other new knowledge, information, or resources that is or are not directly solicited by } \\
\text { discussion topics in question but desired and welcomed by instructors and peers. }\end{array}$ \\
\hline CK & ○ Conceptual Knowledge & $\begin{array}{l}\text { Conceptual knowledge is defined as "the interrelationships among the basic elements } \\
\text { within a larger structure that enable them to function together." }\end{array}$ \\
\hline CK-TM & $\begin{array}{l}\text { - } \text { Theories } \\
\text { - } \quad \text { Models }\end{array}$ & $\begin{array}{l}\text { Theories and models in a discipline or field, which usually are the focus of the to-be- } \\
\text { learned content in a course. }\end{array}$ \\
\hline $\begin{array}{l}\text { CK- } \\
\text { GPR }\end{array}$ & $\begin{array}{ll}\text { - } & \text { Guideline } \\
\text { - } & \text { Principles } \\
\text { - } & \text { Research findings }\end{array}$ & $\begin{array}{l}\text { Well-established guidelines, principles, research findings, and other published sources that } \\
\text { provide similar guidance as those well-established guidelines and principles. }\end{array}$ \\
\hline $\mathrm{CK}-\mathrm{CC}$ & $\begin{array}{ll}\text { - } & \text { Classification } \\
\text { - } & \text { Categories } \\
\end{array}$ & Associated elements that have common or unique characterizations or functionalities. \\
\hline PK & o Procedural Knowledge & $\begin{array}{l}\text { Procedure knowledge is related to "how to do something, methods of inquiry, and criteria } \\
\text { for using skills, algorithms, techniques, and methods". }\end{array}$ \\
\hline PK-EC & $\begin{array}{l}\text { - Evaluation processes/methods } \\
\text { - } \quad \text { Criteria or techniques }\end{array}$ & $\begin{array}{l}\text { Evaluation or data collection methods, criteria and techniques that are used to evaluate } \\
\text { something. }\end{array}$ \\
\hline
\end{tabular}


Table 2 Continued,

\begin{tabular}{|c|c|c|}
\hline$C S$ & - Cognitive Skills & $\begin{array}{l}\text { Cognitive skills are the intellectual or mental activities that process information and } \\
\text { stimuli. }\end{array}$ \\
\hline CS-SDS & $\begin{array}{ll} & \text { Sharing } \\
\circ & \text { Describing } \\
\circ & \text { Seeking information or solutions }\end{array}$ & $\begin{array}{l}\text { At this level, the discussions or postings are more opinions-oriented and without } \\
\text { underlying reasoning, rationale, or explanations. }\end{array}$ \\
\hline $\begin{array}{r}\text { CS-SDS- } \\
\text { RD }\end{array}$ & $\begin{array}{l}\text { - } \quad \text { Referring to } \\
\text { - } \quad \text { Describing }\end{array}$ & $\begin{array}{l}\text { Referring to or describing personal experiences and examples related to discussion topic; } \\
\text { agreeing or disagreeing with others or assigned reading materials without much new } \\
\text { information. }\end{array}$ \\
\hline $\begin{array}{l}\text { CS-SDS- } \\
\text { DCS }\end{array}$ & $\begin{array}{l}\text { - } \text { Describing } \\
\text { - } \quad \text { Communicating } \\
\text { Summarizing or reporting }\end{array}$ & $\begin{array}{l}\text { Simply describing or communicating one's own or others' hypothesis, position, } \\
\text { perspective or opinions without explanation or reasoning; summarizing discussions or } \\
\text { assigned reading materials without much interpretation. }\end{array}$ \\
\hline $\begin{array}{r}\text { CS-SDS- } \\
\text { OA }\end{array}$ & $\begin{array}{l}\text { - Observing } \\
\text { - Asking questions }\end{array}$ & $\begin{array}{l}\text { Taking notice of discussions through, i.e. commenting; asking questions related to } \\
\text { discussions or reading materials. }\end{array}$ \\
\hline CS-ECIC & $\begin{array}{ll} & \text { Explaining } \\
\circ & \text { Comparing } \\
\circ & \text { Interpreting } \\
\circ & \text { Clarifying }\end{array}$ & $\begin{array}{l}\text { At this level, the discussions or postings are ideas, suggestions, perspectives with } \\
\text { underlying reasoning, rationale or personal explanations and examples. }\end{array}$ \\
\hline $\begin{array}{r}\text { CS-ECIC- } \\
\text { PE }\end{array}$ & $\begin{array}{ll}\text { - } & \text { Paraphrasing } \\
\text { - } & \text { Elaborating ideas }\end{array}$ & $\begin{array}{l}\text { The central idea(s) of a posting comes from others or reading materials; the elaborator } \\
\text { further explains the idea(s) or provides additional examples/references to the same idea(s). }\end{array}$ \\
\hline $\begin{array}{r}\text { CS-ECIC- } \\
\text { PSPR }\end{array}$ & 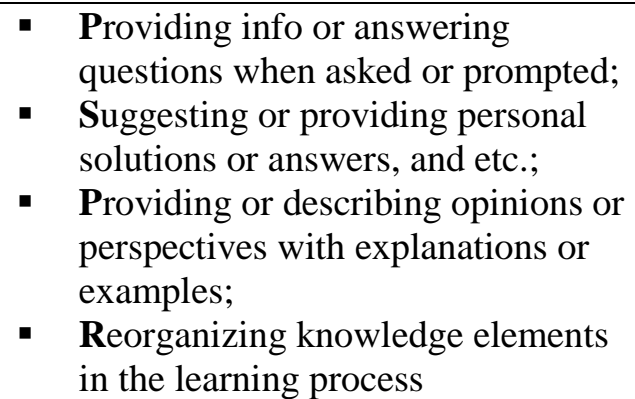 & $\begin{array}{l}\text { The perspective, position hypothesis, suggestion, or observation (with reasoning and } \\
\text { explanations) is more about personal (learning) experience or personal opinions rather } \\
\text { than an application of learned theories/models, etc.; it is not a conclusion or decision } \\
\text { drawn from existing theories, or models, etc. }\end{array}$ \\
\hline
\end{tabular}


Table 2 Continued,

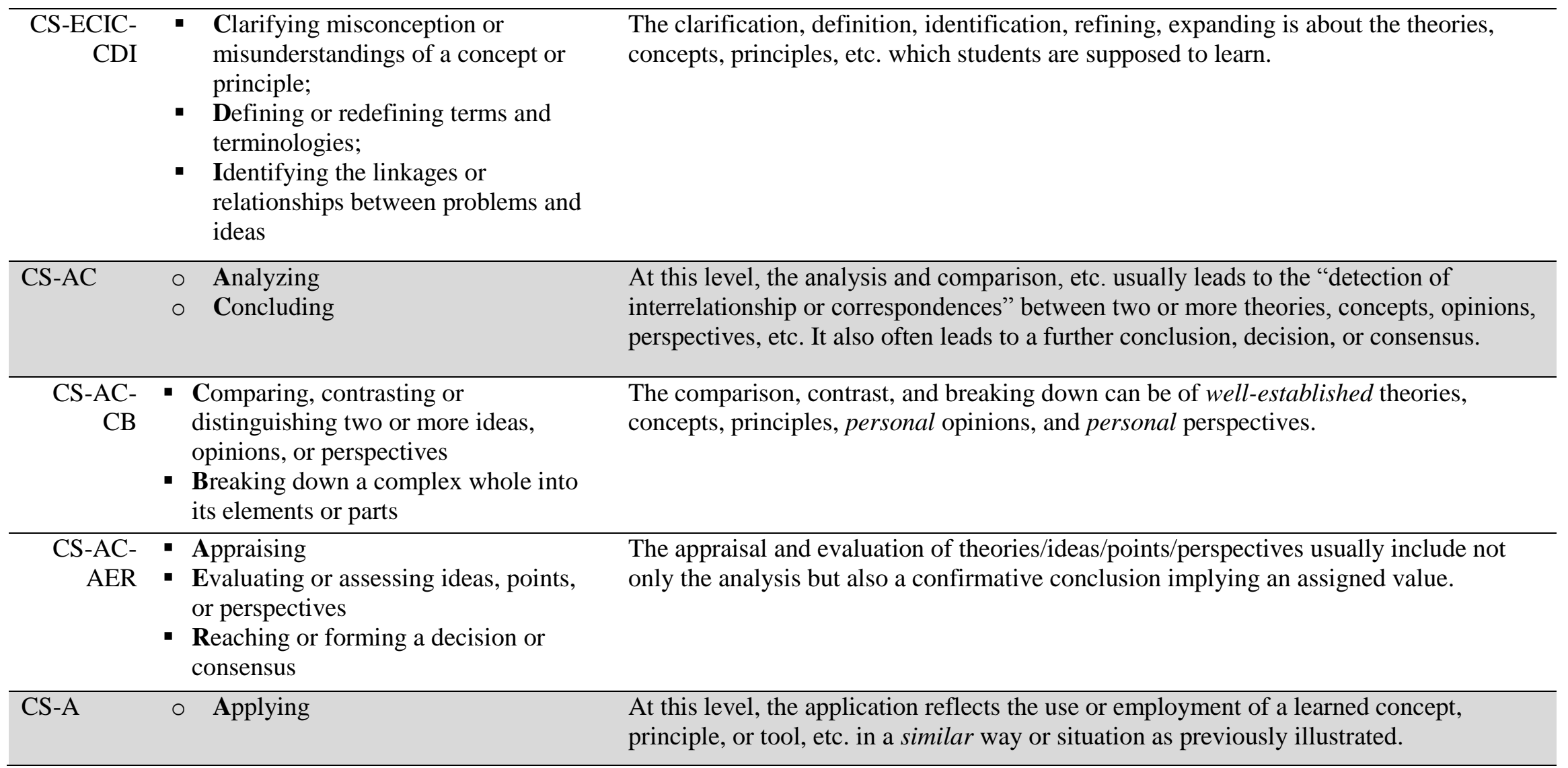


Table 2 Continued,

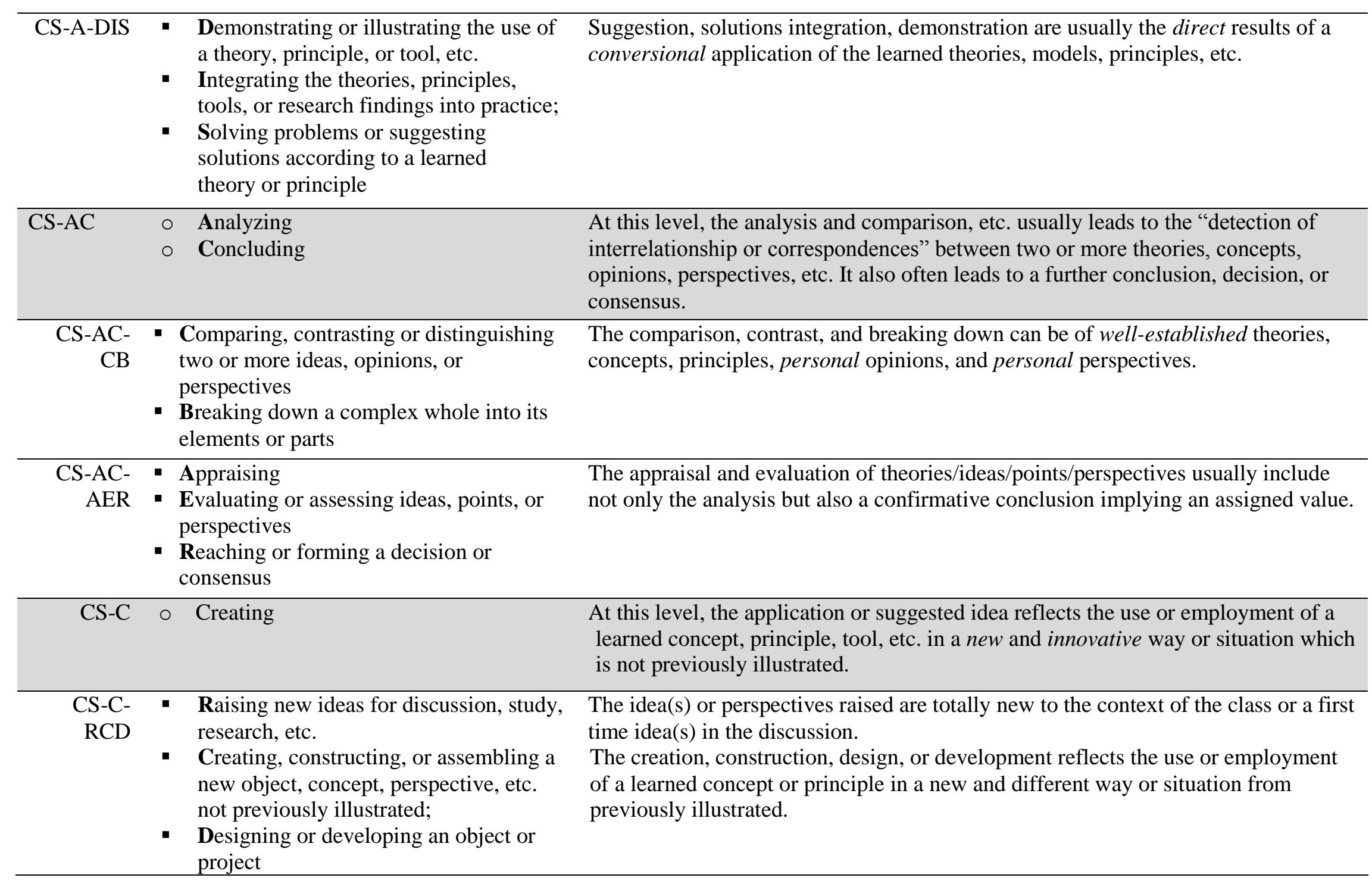


Table 3 Outcomes of chi-square Tests

\begin{tabular}{|c|c|c|c|c|}
\hline Sub-category & chi-square Value & $\begin{array}{c}p \text {-value } \\
(d f=1)\end{array}$ & $\begin{array}{l}\text { Minimum Expected } \\
\text { Frequency } \\
\text { (Rounded to Integers) }\end{array}$ & $\begin{array}{l}\text { Observed Frequency } \\
\text { (Rounded to Integers) }\end{array}$ \\
\hline FK-DT & .75 & .387 & 413 & 425 \\
\hline FK-O & .33 & .563 & 165 & 158 \\
\hline $\mathrm{K}-\mathrm{NI}$ & 5.53 & .019 & 48 & 64 \\
\hline CK-TM & 7.64 & .006 & 85 & 61 \\
\hline CK- GPR & 1.72 & .190 & 42 & 50 \\
\hline $\mathrm{CK}-\mathrm{CC}$ & 1.02 & .314 & 34 & 28 \\
\hline PK-EC & 23.11 & .000 & 42 & 72 \\
\hline CS-SDS-RD & 3.32 & .068 & 141 & 161 \\
\hline CS-SDS-DCS & 2.18 & .140 & 162 & 179 \\
\hline CS-SDS-OA & 1.98 & .160 & 201 & 218 \\
\hline CS-ECIC-PE & 8.43 & .004 & 82 & 57 \\
\hline CS-ECIC-PSPR & 5.99 & .014 & 233 & 266 \\
\hline CS-ECIC-CDI & 13.59 & .000 & 25 & 43 \\
\hline CS-AC-CB & 1.85 & .174 & 34 & 26 \\
\hline CS-AC-AER & 2.26 & .133 & 60 & 49 \\
\hline CS-A-DIS & .88 & .348 & 106 & 115 \\
\hline CS-C-RCD & .01 & .921 & 64 & 65 \\
\hline
\end{tabular}

\section{CFA Measurement Models}

The initial CFA measurement two-factor (i.e., knowledge and cognitive skills) model corresponding to the initial model (see Table 2) is presented in Fig. 2. The knowledge factor has seven indicators and the cognitive skills factor has ten indicators. 


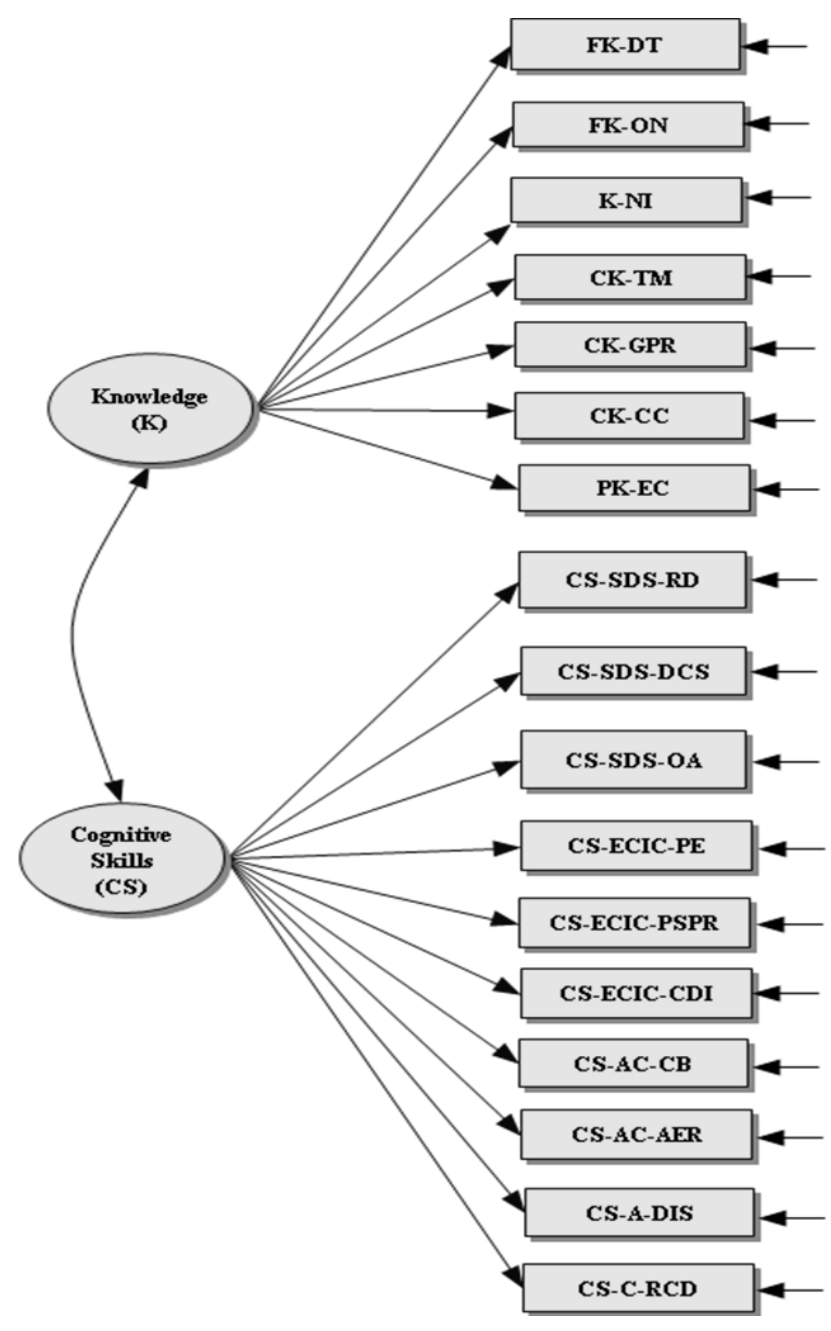

\section{Fig. 2. The Initial Measurement Model for CFA}

We started to examine the initial measurement model through the descriptive data analysis and then chi-square tests. According to the descriptive data analysis (proportions of each sub-category in both sets of data) and chisquare tests, we combined K-NI (K-New knowledge/Information) and FK-O (FK-Other basic disciplinary details) into a new sub-category, FK-ON (FK-Other basic disciplinary details/New knowledge or information). We also combined all three sub-categories of conceptual knowledge (CK-TM, CK-GPR, and CK-CC) into one category CK (Conceptual Knowledge). Similarly, we combined CS-AC-CB (CS -Analyzing/Concluding Comparing, contrasting or distinguishing/Breaking down a complex whole) and CS-AC-AER (CSAnalyzing/Concluding- Appraising/Evaluating or assessing ideas, etc./Reaching or forming a decision, etc.) into CS-AC (CS -Analyzing/Concluding). We excluded sub-categories CS-ECIC-PE (CS -

Explaining/Comparing/Interpreting/Clarifying - Paraphrasing/Elaborating ideas) and CS-ECIC-CDI (CSExplaining/Comparing/Interpreting/Clarifying - Clarifying misconception or misunderstandings/Defining or redefining terms, etc./Identifying the linkages or relationships) from the category CS-ECIC (CS -

Explaining/Comparing/Interpreting/Clarifying) in the initial measurement model according to chi-square test results $(p<0.05)$. Furthermore, we regrouped the sub-category, CS-ECIC-CDI into the category CS-AC according to the "code up" rule (Garrison et al. 2001) because it seemed that CS-ECIC-CDI related more closely to Analysis. However, we did not change the name of the category "ECIC" after the regrouping for easy comparison.

The regrouping of one category and sub-category into another category meant the observed frequency counts generated from one category or sub-category were regrouped into the frequency count of another category or sub-category. This regrouping and excluding of some sub-categories resulted in a modified measurement model (Fig. 3) for CFA with fewer indicators of both knowledge and cognitive skills categories. 


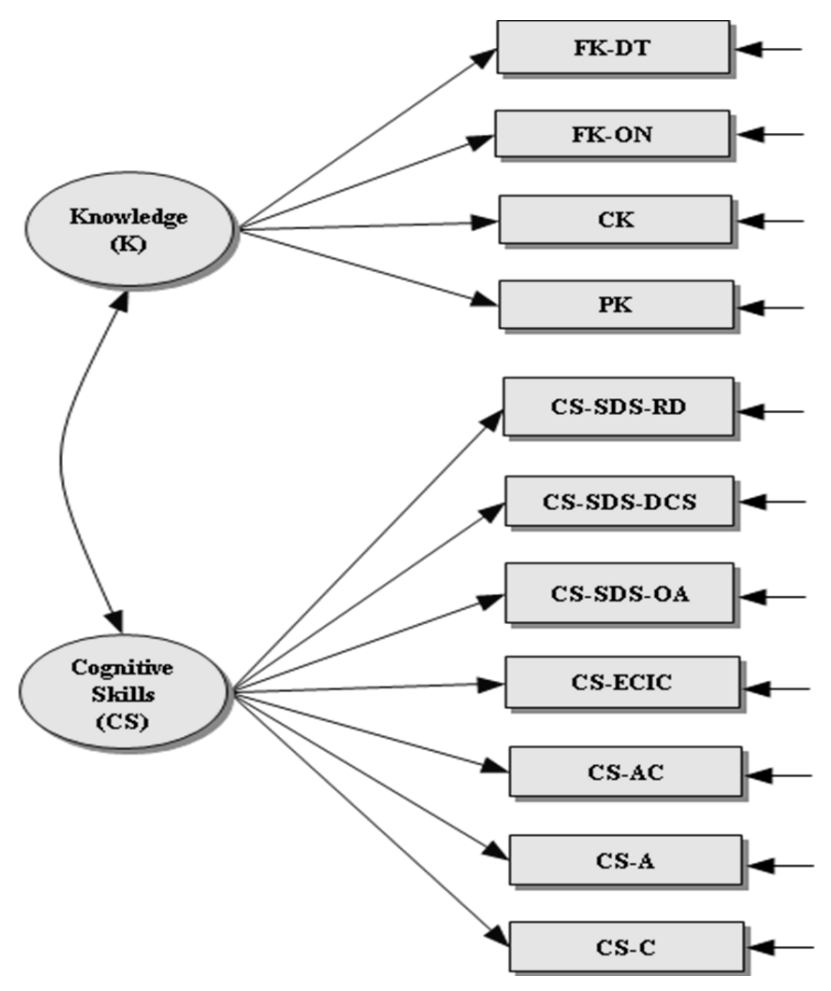

Fig. 3. The Modified Measurement Model for CFA

Outcomes of CFA

The overall fit of the modified measurement model for CFA was evaluated by examining the $\chi^{2} / d f$, RMSEA, GFI, AGFI, and CFI. The modified measurement model showed marginal fit, with $\chi^{2}(43)=170.04, p<.001$, $\chi^{2} / d f=3.95, \mathrm{RMSEA}=0.058, \mathrm{GFI}=0.97, \mathrm{AGFI}=0.95$, and $\mathrm{CFI}=0.74$. Although the chi-square value was quite large and was statistically significant $(p<.001)$, its ratio to the degrees of freedom was acceptable and was less than 4 . The RMSEA value was close to a good fit value of 0.06 . Both the value of GFI and AGFI were larger than a good fit value of 0.90 . The CFI value was 0.74 , which was less than the commonly accepted value of 0.90. However, considering the study was brand new research in terms of using AODs as cases or observations for CFA- it was the first of its kind- a statistic may be acceptable even it is somewhat below a conventional range (Riffe, Lacy and Fico 1998). Thus, examining all the fit indexes together we would conclude that the modified measurement model marginally fit the new sample of data. Consequently, according to the outcomes of CFA and chi-square tests, the initial model from the qualitative process could be regrouped into a modified model (see Table 4), which is more precise. The modified model has six sub-categories of knowledge and nine sub-categories of cognitive skills. 
Table 4 The Modified Model according to the Quantitative Results

\begin{tabular}{|c|c|}
\hline Code & Category and Sub-category \\
\hline$K$ & - Knowledge \\
\hline \multirow[b]{2}{*}{ FK-DT } & ○ Factual Knowledge \\
\hline & $\begin{array}{ll}\text { - } & \text { Definitions } \\
\text { - } & \text { Terminologies }\end{array}$ \\
\hline FK-ON & $\begin{array}{l}\text { - Other basic disciplinary details } \\
\text { - New knowledge or information }\end{array}$ \\
\hline CK & ○ Conceptual Knowledge \\
\hline CK-TM/GPR/CC & $\begin{array}{l}\text { - } \text { Theories } \\
\text { - Models } \\
\text { - Guidelines } \\
\text { - Principles } \\
\text { - Research findings } \\
\text { - Classifications } \\
\text { - Categories }\end{array}$ \\
\hline PK & o Procedural Knowledge \\
\hline PK-EC & $\begin{array}{l}\text { - Evaluation processes or methods } \\
\text { - Criteria or techniques }\end{array}$ \\
\hline
\end{tabular}

\begin{tabular}{ll}
\hline$C S$ & $\bullet$ Cognitive Skills \\
\hline CS-SDS & $\circ$ Sharing \\
& $\circ$ Describing \\
& $\circ$ Seeking information or solutions \\
\hline CS-SDS-RD & - Referring to \\
& - Describing \\
\hline CS-SDS-DCS & - Describing \\
& - Communicating \\
& - Summarizing or reporting
\end{tabular}

\begin{tabular}{lll}
\hline CS-SDS-OA & - Observing \\
& - Asking questions \\
\hline CS-ECIC & $\circ$ Explaining \\
& $\circ$ Comparing \\
& $\circ$ Interpreting \\
& $\circ$ Clarifying \\
& & \\
\hline CS-ECIC-PSPR & - Providing info or answering questions when asked or prompted; \\
& - Suggesting or providing personal solutions or answers, and etc.; \\
& - Providing or describing opinions or perspectives with explanations or \\
& - examples; \\
& $\circ$ Analyzing \\
& $\circ$ Concluding \\
\hline CS-AC &
\end{tabular}




\begin{tabular}{|c|c|}
\hline $\begin{array}{r}\text { CS-AC- } \\
\text { CDI/CB/AER }\end{array}$ & $\begin{array}{l}\text { - Clarifying misconception or misunderstandings of a concept or principle; } \\
\text { - Defining or redefining terms and terminologies; } \\
\text { - Identifying the linkages or relationships between problems and ideas } \\
\text { - Comparing, contrasting, or distinguish two or more ideas, opinions, or } \\
\text { - perspectives; } \\
\text { - Breaking down a complex whole into its elements or parts } \\
\text { - Appraising } \\
\text { - Evaluating or assessing ideas, points, or perspectives; } \\
\text { - Reaching or forming a decision or consensus }\end{array}$ \\
\hline CS-A & $\begin{array}{ll}\text { Applying } \\
\end{array}$ \\
\hline CS-A-DIS & $\begin{array}{l}\text { Demonstrating or illustrating the use of a theory, principle, or tool, etc.; } \\
\text { - Integrating the theories, principles, tools, or research findings into } \\
\text { practice; } \\
\text { - Solving problems or suggesting solutions according to a learned theory } \\
\text { or principle }\end{array}$ \\
\hline $\mathrm{CS}-\mathrm{C}$ & ○ Creating \\
\hline CS-C-RCD & $\begin{array}{l}\text { - Raising new ideas for discussion, study, research, etc.; } \\
\text { - Creating, constructing, or assembling a new object, concept, } \\
\text { perspective, etc. not previously illustrated; } \\
\text { - Designing or developing an object or project }\end{array}$ \\
\hline
\end{tabular}

\section{Discussion}

\section{Comparing the Model being Constructed and Tested to Previous Models}

The model being constructed and tested has both differences and similarities when compared to the other four major existing models or frameworks for AODs. One of the main differences between this model and the others is that the new model has a two-dimensional structure that assesses not only cognitive skills but also knowledge. The two-dimensional structure reflects students' internal representations of knowledge and cognitive skills and their external representations (Pirnay-Dummer, Ifenthaler and Spector 2009). Thus, the new model has both practicality and completeness when compared to the other four models or frameworks. It is applicable for assessing general AODs as well as debates and discussions related to problem-solving activities.

One of the main similarities between the new model and the other four existing models or frameworks is that they were all created to assess the cognitive aspect of students' learning in AODs. All the models, excluding Newman et al.'s (1996) Framework, consist of different levels (categories) of cognitive learning. For example, Henri's Cognitive Framework (1992) and Gunawardena et al.'s IAM (1997) both have five levels (categories) of cognitive skills with respective indicators. Garrison et al.'s (2001) Model has four levels (categories) of cognitive skills. The new content analysis model has five levels (categories) of cognitive skills, which is consistent with the other models or frameworks.

While initially this new model and the revised Bloom's Taxonomy (Anderson and Krathwohl 2001) may look similar as they both include a two-dimensional structure for knowledge and cognitive skills, several differences also exist. Using a two-dimensional structure for assessing the cognitive aspect of learning accommodates the need for more indicators of learning. However, the categories and sub-categories in the new model have different meanings and explanations from those in the revised Bloom's Taxonomy because the new model was created for the explicit purpose of assessing AODs.

This new model could be useful for both online instructors and students. Although it has three categories of knowledge and five categories of cognitive skills and each category has its own sub-categories, there are explanations for each category and sub-category. The explanations were created with a focus on easy separation of categories and sub-categories so the users can easily tell apart one category or sub-category from the other(s). In addition, when using this model, it does not require one posting to have all or most of the indicators to be labeled with one category or sub-category (level). Thus, it could be used in a timely fashion. However, more detailed guidelines for how to use this model for the purpose of grading are still needed. The explanations of 
each category or sub-category can also serve as a guideline for students because they have the criteria for classifying different levels of learning. For example, the explanation for the level CS-SDS is without any reasoning or support, while the level of CS-ECIC is with underlying reasoning and support. Prompting students to provide underlying reasoning and support might improve the overall discussion.

\section{Reliability and Validity of the Content Analysis Model Constructed and Tested}

For the purpose of research, the validity and reliability issues of content analysis models may be less serious than those of a grading instrument or rubric. As an assessment instrument or grading rubric, a content analysis model should have the appropriate reliability and validity evidence (Marra et al. 2004; Marra 2006) to support the resulting scores and inferences based on those scores. In this study, the development of the new content analysis model followed a series of steps and procedures that provided "standardization and rigor" (Strauss and Corbin 1998, p.13) and ensured the "trustworthiness, rigor and quality" (Golafshani 2003, p.604) during the process of the model development.

First, the selection of discussion topics arrived at following the experts' review ensured the content validity of discussion topics, i.e. selected discussion topics measured what they were supposed to measure (Brown 1996). Consequently, the selection of discussion topics resulted in quality online postings which were used to develop a reliable content analysis model. Second, during the process of the model construction, steps and procedures of a grounded theory were followed, which provided guidelines and rigor of the model development (Golafshani 2003). The inter-coder reliability checks and resolution and the computing of the Cohen's alpha also demonstrated the rigor of the model construction process. Third, the experts' review and revisions of the initial model according to experts' reviews helped to ensure and improve reliability and construct validity aspects of the model in the sense that the categories and sub-categories were representative of knowledge and cognitive skills. Thus, we have initial evidence that the model will assess the essential aspects of such discussions in a given AOD environment. Evidence also suggests that such a model can be employed by different raters and consistent ratings can be obtained.

\section{The Modified Measurement Model for CFA}

The modified measurement model for CFA resulted from a process of regrouping and excluding some subcategories of learning. However, the regrouping and exclusions of six sub-categories using the $10 \%$ cut-off value was rather intuitive and arbitrary. In addition, $21 \%$ of the online postings in the quantitative data only contained one or two sentences and were coded into either CS-SDS-DCS or CS-SDS-OA sub-categories. These short postings might have contributed to the fact that some sub-categories had small proportions of occurrences in the data. Consequently, some sub-categories might have been falsely regrouped or excluded from the initial measurement model due to their small proportions when forming the modified measurement model. If all postings had been longer, all sub-categories might have had larger proportions because the longer the postings were, the more likely it was they would reveal more different levels of cognitive learning. Subsequently, a different modified measurement model might have resulted from the regrouping and excluding progress.

Although three out of five fit indexes (RMSEA, GFI, and AGFI) showed that the modified measurement model adequately fit the quantitative data and the ratio of chi-square to the degrees of freedom (3.95) indicated fair fit, cautions against the use and application of the modified measurement model should be emphasized. This is due to two factors: 1) the intuitive regrouping of six sub-categories that had small proportions, and 2) the less than conventionally accepted CFI value. Thus, other models may also need to be considered and tested.

\section{Future Research}

This study had several limitations that might have affected the analysis results and consequently the outcomes of the study. First, the content analysis model was constructed through a grounded theory approach. During the analysis of online postings, the researchers might have developed certain categories and sub-categories and grouped certain concepts into certain categories and sub-categories according to their own biases and experiences.

Second, in the AODs, students only had one week or less to discuss specific discussion topics, compile, and post their responses. Higher levels of cognitive learning, especially at the level of Creating, might have appeared less frequently because students did not have enough time to ponder discussion topics and come up with innovative ideas. Third, results of the descriptive data analysis showed that some sub-categories had small proportions of occurrence, which indicated that distributions of observed variables in quantitative data were skewed. Such sample data limited the quantitative methodology, especially the CFA, and interpretation of the modified 
measurement model. Such sample data (e.g., short postings due to time constraints and the lack of specific levels of learning) might also be one of the reasons why there had been no previous use of CFA in the development of content analysis model. Finally, the study was conducted at a university and within formal educational settings. The two chosen graduate online courses were from the same academic discipline, Educational Technology, which may pose some constraints for the wider application of the results.

Based on the above limitations, we make the following recommendations for future studies. First, future research on content analysis models using AODs could pose a requirement on the length of AODs as well as the number of AODs. However, strategies that motivate students to post relatively long and meaningful AODs should also be considered in such situations. Second, future studies could give students more time, preferably two weeks or more, to work on the same discussion topic(s) before moving on to the next discussion topic(s). As for the short postings, future researchers may need to impose a length requirement for students' online postings in addition to the requirement for the number of postings, since the longer postings have a better chance of revealing more sub-categories of cognitive learning. Future researchers who will use online postings as cases or observations in CFA or any other inferential analyses should make sure that online postings are long enough to reveal many different levels of cognitive learning. Third, future studies could separate discussion topics for knowledge acquisition from those for cognitive skills. With different sets of data for both knowledge and cognitive skills, a three-factor (FK, CK, and PK) CFA and another five-factor (CS-SDS, CS-ECIC, CS-AC, CSA, and CS-C) CFA could be conducted, respectively. Fourth, similar studies are recommended at different levels, such as undergraduate and secondary levels. Fifth, similar studies are also recommended with learning objectives in the affective and psychomotor domains. It would be interesting to compare different content analysis models that are derived from different levels and in different domains of learning. Sixth, different researchers are encouraged to provide additional reliability evidence for the new model. Last but not the least, future studies on how to develop an automated assessment tool for assessing knowledge acquisition and cognitive skills in AODs are encouraged.

\section{Conclusions}

This study has the following contributions due to its unique context, the assessment focus and the validation procedures and process it adopted. Specifically, the new model was derived from semester-long general discussions other than several-week's debates or problem-solving discussions, or no real context - such as some models were derived theoretically. The model has a different assessment focus, both on knowledge and all levels of cognitive skills - other than higher levels of skills. The study has adopted a series of procedures and a validation process which were not used in previously similar studies.

The new model has indicators of cognitive learning for different levels of both knowledge and cognitive skills. In this sense, this study contributes to practice by providing a more complete content analysis model than was previously available. The study also contributes to practice by providing a reliable and valid content analysis model in terms of the scores it generates. The study may also contribute to the development of automated tools and models for assessing knowledge acquisition and cognitive skills in online discussions by providing potential key terms or words for an automated content analysis process (Clariana, Wallace and Godshalk 2009).

Most importantly, this study used online postings as cases or observations instead of participants in CFA to test the modified model. The use of online postings as cases or observations avoided the pitfall that most similar studies have insufficient number of participants (insufficient sample) as data inputs for CFA and was the first of its kind. This method has important implications in terms of providing empirical lessons for future studies, especially quantitative studies and the process of regrouping and excluding some categories and sub-categories (observed variables) to formulate modified measurement models. 


\section{References}

Allen, E., \& Seaman, J. (2008). Staying the course: Online education in the United States, 2008. Retrieved December 29, 2008, from http://sloan-c.org/publications/survey/pdf/staying_the_course.pdf

Anderson, J.G. (n.d.). Measurement Models: Exploratory and Confirmatory Factor Analysis. Retrieved March 28, 2008, from http://web.ics.purdue.edu/ janders1/Soc681/Measurement\%20Models.ppt

Anderson, L. W., \& Krathwohl, D. R. (Eds.) (2001). A taxonomy for learning, teaching, and assessing: A revision of Bloom's taxonomy of educational objectives. New York: Longman.

Anderson, T. (2008). Teaching in an online learning context. In T. Anderson (Ed.), The theory and practice of online learning $\left(2^{\text {nd }}\right)$ (pp. 343-365). Athabasca University, AU.

Armour-Thomas, E. (1986). Toward a qualitative analysis of standardized tests using an information processing model. ERIC Document Reproduction Service No. ED286933.

Barbera, E. (2006). Collaborative knowledge construction in highly structured virtual discussions. Quarterly Review of Distance Education, 7(1), 1-12.

Bentler, P. M. (1990). Comparative fit indexes in structural models. Psychological Bulletin, 107, 238-246.

Bloom B. S. (1956). Taxonomy of educational objectives. Handbook I: The cognitive domain. New York: David McKay.

Brown, J. D. (1996). Testing in language programs. Upper Saddle River, NJ: Prentice Hall Regents.

Clariana, R. B., Wallace, P. E., \& Godshalk, V. M. (2009). Deriving and measuring group knowledge structure from essays: the effects of anaphoric reference. Educational Technology Research and Development. Retrieved April 12, 2009, from http://www.springerlink.com/content/x4t20q1936521447/fulltext.pdf

Corich, S., Kinshuk, \& Hunt, L. M. (2006). Measuring critical thinking within discussion forums using a computerised content analysis tool. Retrieved November 12, 2006, from http://www.networkedlearningconference.org.uk/abstracts/pdfs/P07\%20Corich.pdf

Council for Higher Education Accreditation (CHEA), (2002). Student learning outcomes workshop [Electronic Version]. CHEA Chronicle, 5(2), 1-3. Retrieved November 18, 2006, from http://www.chea.org/Chronicle/vol5/no2/Chron-vol5-no2.pdf

DeCoster, J. (1998). Overview of factor analysis. Retrieved March 31, 2008, from http://www.stat-help.com/factor.pdf

Facione, P. A., Facione, N. C., \& Giancarlo, C. A. (2000). The disposition toward critical thinking: Its character, measurement, and relationship to critical thinking skill. Informal Logic, 20(1), 61-84.

Facione. P. A., Giancarlo C.A., Facione N.C., \& Gainen J. (1995). The disposition toward critical thinking. Journal of General Education, 44, 1-25.

Garrison, D. R. (1992). Critical thinking and self-directed learning in adult education: an analysis of responsibility and control issues. Adult Education Quarterly, 42(3), 136-148.

Garrison, D. R. (2003). Cognitive presence for effective asynchronous online learning: the role of reflective inquiry, self-direction and metacognition. In J. Bourne \& J. C. Moore (Eds.), Elements of quality online education: Practice and direction (pp. 47-58). Needham, MA: Sloan Center for Online Education.

Garrison, D. R., Anderson, T., \& Archer, W. (2000). Critical inquiry in a text-based environment: Computer conferencing in higher education. The Internet and Higher Education, 2(2-3), 87-105.

Garrison, D. R., Anderson, T., \& Archer, W. (2001). Critical thinking, cognitive presence, and computer conferencing in distance education. American Journal of Distance Education, 15(1), 7-23.

Glaser, B. G., \& Strauss, A. L. (1967). The discovery of grounded theory: Strategies for qualitative research. Chicago: Aldine.

Golafshani, N. (2003). Understanding reliability and validity in qualitative research. The Qualitative Report, $8(4), 597-606$.

Gunawardena, C. N., Lowe, C. A., \& Anderson, T. (1997). Analysis of global online debate and the development of an interaction analysis model for examining social construction of knowledge in computer conferencing. Journal of Educational Computing Research, 17(4), 397- 431.

Hanson, W. E., Creswell, J. W., Plano-Clark, V. L., Petska, K. S., \& Creswell, J. D. (2005). Mixed methods research designs in counseling psychology. Journal of Counseling Psychology, 52, 224-235.

Henri, F. (1992). Computer conferencing and content analysis. In A. Kaye (Ed.) Collaborative learning through computer conferencing: The Najaden papers (pp.117-136). London: Springer-Verlag.

Hu, L., \& Bentler, P. M. (1999). Cut-off criteria for fit indexes in covariance structure analysis: Conventional criteria versus new alternatives. Structural Equation Modeling, 6(1), 1-55.

Joreskog, K. G., \& Sorbom, D. (2001). LISREL 8: Users' reference guide. Chicago: Scientific Software International. 
Kane, M. T. (2006). Validation. In R. L. Brennan (Ed.), Educational measurement (4 ${ }^{\text {th }}$ ed) (pp. 17-64). Westport: American Council on Education and Praeger.

Marra, R. (2006). A review of research methods for assessing content of computer-mediated discussion forums. Journal of Interactive Learning Research, 17(3), 243-267.

Marra, R. M., Moore, J. L., \& Klimczack, A. K. (2004). Content analysis of online discussion forums: A comparative analysis of protocols. Educational Technology Research and Development, 52(2), 23-40.

Mazur, J. (2004). Conversation analysis for educational technologists: theoretical and methodological issues for researching the structures, processes and meaning of on-line talk. In D. H. Jonassen (Ed.), Handbook for Research in Educational Communications and Technology (2nd ed) (pp.1073-1099). Mahwah, NJ: Lawrence Erlbaum Associates.

McLoughlin, C., \& Luca, J. (2000). Cognitive engagement and higher order thinking through computer conferencing: We know why but do we know how? Retrieved October 2, 2006, from http://lsn.curtin.edu.au/tlf/tlf2000/mcloughlin.html

McPeck, J. (1981) Critical thinking and education. New York: St. Martin's.

Miles, M. B., \& Huberman, A. M. (1994). Qualitative data analysis ( $2^{\text {nd }}$ ed.). Thousand Oaks, CA: Sage.

Moallem, M. (2005). Designing and managing student assessment in online learning environment. In Comeaux, P. (Ed.), Assessing online learning (pp.18-34). Bolton, MA: Anker.

Moore, M. G. (1989). Three types of interaction [Electronic version]. The American Journal of Distance Education, 3(2). Retrieved January 24, 2005, from http://www.ajde.com/Contents/vol3 2.htm\#editorial

Newman, D. R., Webb, B., \& Cochrane, C. (1996). A content analysis method to measure critical thinking in face-to-face and computer supported group learning. Retrieved October 5, 2006, from http://www.qub.ac.uk/mgt/papers/methods/contpap.html

Pallant, J. (2007). SPSS survival manual ( $3^{\text {rd }}$ ed.). McGraw Hill: Open University.

Pandit, N. R. (1996). The creation of theory: a recent application of the grounded theory method. Qualitative Report, 2(4). Available on line at http://www.nova.edu/ssss/QR/QR2-4/pandit.html

Pirnay-Dummer, P., Ifenthaler, D., \& Spector, J. M. (2009). Highly integrated model assessment technology and tools. Educational Technology Research and Development. Retrieved April 12, 2009, from http://www.springerlink.com/content/6005268510618175/fulltext.pdf

Riffe, D., Lacy, S., \& Fico, F. (1998). Analyzing media messages: Quantitative content analysis. New Jersey: Lawrence Erlbaum.

Reeves, T.C. (2000). Alternative assessment approaches for online learning environments in higher education. Journal of Educational Computing Research, 23(1), 101-111.

Rourke, L., Anderson, T., Garrison, D. R., \& Archer, W. (2001). Methodological issues in the content analysis of computer conference transcripts. International Journal of Artificial Intelligence in Education, 12, 8 22.

Savenye, W. C. (2004). Alternatives for assessing learning in Web-based courses. Distance Learning, 1(1), 2935.

Schumacher, B. K., West, D. V., \& Angell, L.R. (1997, November). Assessing knowledge and cognitive skills. Paper presented at the Annual Meeting of the National Communication Association, Chicago, IL. ERIC Document Reproduction Service No. ED417429.

Scientific Software International. (2008). Retrieved June 12, 2008, from http://www.ssicentral.com/

Strauss, A., \& Corbin, J. (1998). Basics of qualitative research: Techniques and procedures for developing grounded theory (2nd ed.). Thousand Oaks, CA: Sage.

Swan, K., Shen, J., \& Hiltz, S. R. (2006). Assessment and collaboration in online learning [Electronic Version]. Journal of Asynchronous Learning Networks, 10(1), 45-62. Retrieved November 12, 2006 from http://www.sloan-c-wiki.org/JALN/v10n1/pdf/v10n1_5swan.pdf

Swan, K., Schenker, J., Arnold, S., \& Kuo, C-L. (2007). Shaping online discussion: assessment matters. Ementor, 1(18). Retrieved December 12, 2006, from http://www.e-mentor.edu.pl/_xml/wydania/18/390.pdf

The Cognitive Aptitude Assessment Software Glossary (CAASG). (2006). Educational Help, Inc. Available from http://www.cognitive-aptitude-assessment-software.com/Glossary/CognitiveSkills.html

Wijekumar, K., Ferguson, L. \& Wagoner, D. (2006). Problems with assessment validity and reliability in Webbased distance learning environments and solutions. Journal of Educational Multimedia and Hypermedia, 15(2), 199-215. Chesapeake, VA: AACE.

Yang, Y. C., (2008). A catalyst for teaching critical thinking in a large university class in Taiwan: asynchronous online discussions with the facilitation of teaching assistants. Educational Technology Research and Development, 56, 241-264. 


\title{
Appendix A: Sample Discussion Questions
}

\section{Sample Discussion Questions for Course IMCE}

\author{
1. Discussion Question: Technology and Learning
}

What do you think is the role of technology in learning? Looking back on Robyler's chapter \#1 (4th edition), frame your response in terms of method (constructivist or directed, or another method), learner level, and cite a specific learning theorist from the chapter as a means (or example) of expressing your viewpoint.

\section{Discussion Question: How Technology Can Facilitate Learning}

After reading the Johnson \& Johnson article, what are your views on group composition impact on cooperative learning, and how it relates to technology (e.g. does it differ when you use technology)? Take some time to think and formulate a position on technology and cooperative learning, tie it into the readings (past and present) and let us know what you think.

\section{Discussion Question: Technology Planning}

It appears that planning and teamwork are keys to effectively implementing technology into the classroom. How successful can an educator be at accomplishing technological integration if s/he does not have district or even team support? What are some ways that teachers can be effective at accomplishing this goal if they are 'flying solo'? For those of you that are administrators, what other considerations do you think should be included at the school level and why? Support your points.

\section{Sample Discussion Questions for Course FDE}

\section{Discussion Question: Learning Theories and Practical Applications in Online}

Thinking ahead to your final project, or at least the general topic at this point, consider a way in which you would integrate both the behaviorist learning theory and the cognitivist learning theory for particular activities (e.g. one activity for each theory). Which strategies would you utilize when integrating (based on the strategies in your readings associated with each learning theory). It is also important to consider that you may not have use for both (or either?) of these learning theories in your learning module - of not, why not? I'm hoping you will reflect on what each theory does have to offer and have an understanding of what they look like when implemented. Now, after you've done your part, look to your peers and see if you can come up with some suggestions for them as well. Since you will be working in small groups you'll also have to have someone willing to serve as the wrapper for each small group and provide the summary to the larger group.

\section{Discussion Question: Your Theory of Online Learning: What's Important to You?}

This week let's consider several new questions that will help you develop an individualized theory for online learning. Start by considering the Prensky piece on page 50 of Anderson ("how people learn what"), and then the Bransford piece on page 54, Table 2-1 ("how people learn"). Are you taking a learner-centered, communitycentered, knowledge-centered, or assessment centered-approach to your module (there is no right or wrong answer). Now, let's incorporate interaction and presence. I think that all of us have discussed presence at some point in the class, whether we labeled as such or not. Thinking about your online learning modules, what can you do to improve presence? Or, is presence an important part of your module? What kind of presence is important to you for this project and/or in general (instructor, peer, other?).

\section{Discussion Question: Assessment of Online Discussions}

Give your recommendations and offer your ideas to the following scenario. Be sure to provide a justification and rationale based on learning and instructional theories as well as course readings. Please cite appropriately for your justifications and rationale.

Dr. Melinda Smith teaches an online graduate course, Contemporary English Literature. In this online course, the major learning activity is the weekly online discussion and postings on the assigned learning materials. Melinda knows that "if you build it, they will come" doesn't apply to most online 
discussions, instead she believes that "if you don't grade it, they won't come". Nonetheless, she struggles with the different rubrics available for grading the students' online postings and the assignment of the final grades.

Reflective questions: 1) What should Melinda consider when choosing or creating her grading rubrics for the students' online postings? 2) What are the alternatives Melinda could consider for evaluating students' learning in this online course? 3) What would you suggest the percentage of online discussion points be in relation to the final grade? 


\section{Appendix B: Initial Coding Scheme with Examples}

\begin{tabular}{|c|c|c|}
\hline Code & Category and Sub-category & Example \\
\hline$K$ & Knowledge & \\
\hline FK & - Factual Knowledge & \\
\hline FK-D & ○ Definitions & $\begin{array}{l}\text { Instructional design model is a systematic process of planning, developing, and } \\
\text { designing instruction... }\end{array}$ \\
\hline FK-T & $\begin{array}{l}\text { Terminologies of a discipline } \\
\end{array}$ & Course management system(CMS) \\
\hline FK-I & $\circ$ Issues of a field/discipline & $\begin{array}{l}\ldots \text { problems of online tests... the lack of access to computer, and the lack of money } \\
\text { and time... }\end{array}$ \\
\hline FK-TR & $\circ \quad$ Trends of a field/discipline & $\begin{array}{l}\text { Digital devices, such as PEA, ICAL, GIS and some others will be available in } \\
\text { assisting learning and teaching in the near future... }\end{array}$ \\
\hline CK & - Conceptual Knowledge & \\
\hline CK-TM & $\begin{array}{ll}\text { Theories/Models } \\
\end{array}$ & Gardner's multiple intelligences... \\
\hline CK- GP & ○ $\quad$ Guidelines/Principles & $\begin{array}{l}\text {..Fahy (2003) suggested } 13 \text { strategies to improve a sense of community and } \\
\text { collaboration including: acknowledgement, agreement, apology/self-criticism... }\end{array}$ \\
\hline CK-CC & ○ Classifications/Categories & I think you have negative reinforcement confused with punishment. \\
\hline PK & - Procedural Knowledge & \\
\hline PK-EM & ○ Evaluation processes/Methods & ...teacher and students surveys... and open-ended survey and focus group... \\
\hline PK-CT & ○ $\quad$ Criteria/Techniques & $\begin{array}{l}\text { Online discussion should at least account for } 20 \% \text { of the final grade in such an } \\
\text { online course... }\end{array}$ \\
\hline K-NI & - New knowledge/Information & $\begin{array}{l}\text { Educational leadership article, listen to the Natives, by Marc Prensky - coined the } \\
\text { terms digital native (students) and digital immigrants (teachers). }\end{array}$ \\
\hline
\end{tabular}




\begin{tabular}{ll}
\hline CS-SDS & - Sharing/Describing \\
& Seeking information/solutions
\end{tabular}

CS-SDS-RD $\bigcirc \quad$ Referring to/Describing personal/others experiences related to a discussion topic

CS-SDS-DCS ○ Describing/communicating one's own /others' perspective, hypothesis or position without explanation/reasoning;

- Summarizing discussions or reading materials
Yeah for LEGO Mindstorms!!! I'm an advisor for xxx FIRST programs here on campus and I deal mostly with the middle school kinds and LEGO League!!! .. However, I'm only allowed to facilitate and guide them towards

solutions. ...But the best part is that students work as teams using technology and programming to solve problems. ...

It sounds as if you are saying that a key to making the one-computer classroom work well is definitely the planning and time-management. I like the time card idea. It sounds as if that would be a successful means of teaching the student to respect their time on the computer and focus on their work.
CS-SDS-AO $\bigcirc$ Asking questions;

○ Observing questions/others' postings
Very wise suggestions. As a student I would feel related and worry-free if I know the first discussion question is only for practice. It would probably help Adam's students open up on the discussion board. What if some students decide not to participate if they know it will not be graded? Is there a way to prevent nonparticipation in this situation?...

\begin{tabular}{|c|c|c|}
\hline CS-ECIC & $\begin{array}{l}\text { Explaining/ } \\
\text { Comparing/Interpreting/Clarifying }\end{array}$ & \\
\hline CS-ECIC-PE & $\begin{array}{ll}\circ & \text { Paraphrasing; } \\
\circ & \text { Elaborating ideas }\end{array}$ & $\begin{array}{l}\text { Until you mentioned it I never realized (lame of me) that there would be classes } \\
\text { where the students do not see or hear from their instructor during discussions. I } \\
\text { mean, I know there are bad classes where you cannot find the instructor for } \\
\text { weeks on end, but in a good class I would expect the teacher to be in and out all } \\
\text { the time. }\end{array}$ \\
\hline
\end{tabular}


CS-ECIC-RPPS $\bigcirc$ Reorganizing knowledge elements in the learning process;

○ Providing/describing opinions/perspectives with explanations/examples;

$\circ \quad$ Providing info/answering questions when asked;

○ Suggesting a solution, etc.
The smart board is the ever popular technology piece of the moment it seems. What little experience I have with them makes me believe that this would be an excellent tool for those needing the body movement. The use of the markers and the feel of what it's like on the board would reinforce whatever learning concept is being addressed.
CS-ECIC-CDI

○ Clarifying misconception/misunderstandings;

○ Defining/redefining terms/terminologies;

$\circ \quad$ Identifying the linkages/relationships between problems/ideas
I would have to say it is not technology that changed our behavior; indeed it is the way with which we handle and use technology that demonstrates inappropriate behavior. Technology is only a tool, just like a car. We can't blame the car for causing accidents. It is how we operate the care and precaution we take to avoid accidents that saves from catastrophes. ...

\begin{tabular}{|c|c|c|}
\hline CS-AC & - Analyzing/Concluding & \\
\hline CS-AC-CB & $\begin{array}{ll} & \text { Comparing/contrasting/distinguishing two } \\
\text { ideas /opinions / perspectives }\end{array}$ & $\begin{array}{l}\text { I believe as well that the benefits of having a computer for every student far } \\
\text { outweigh the advantages to a one computer classroom.... If you dealing with a } \\
\text { one computer classroom and the technology doesn't work, then you have no } \\
\text { access. If you are using a multiple-computer classroom, then if one or two } \\
\text { machines go down, access is still available and the lesson can continue... }\end{array}$ \\
\hline CS-AC-AER & $\begin{array}{ll} & \text { Appraising } \\
\circ & \text { Evaluating/assessing ideas/points/perspectives } \\
\circ & \text { Reaching/forming a decision/consensus }\end{array}$ & $\begin{array}{l}\text { I look at how distance learning is already greatly affecting the Educational } \\
\text { Technology program in that there are many teachers who are able to take courses } \\
\text { through the program via online course when these teachers may not live nearby } \\
\text { the university. It definitely opens up many options and even more for the } \\
\text { students still in high school and in lower grade levels. Also it may provide } \\
\text { opportunity for smaller schools who may not have the teaching resources to } \\
\text { cover more advanced areas of certain subjects... }\end{array}$ \\
\hline
\end{tabular}


CS-A-DIS $\circ$ Demonstrating/illustrating the use of a theory/principle/tool, etc.

- Integrating the theories/principles/tools/research findings into practice

- Solving problems/suggesting solutions according to a learned theory/principle ...the idea of ITV caught my attention. It caught my attention in terms of the students I currently teach. I could see using it with my current students for areas like story comprehension, sequencing, math skills-right now we use the computer in these areas but for student to be able to view things on the TV screen and answer questions via that screen makes issues like cooperative learning and conversation between the students so much more viable...

\begin{tabular}{|c|c|c|c|}
\hline CS-C & - & Creating & \\
\hline CS-C-CDR & o & $\begin{array}{l}\text { Creating/constructing/assembling a new } \\
\text { object/concept/perspective, etc. based on } \\
\text { previously illustrated ideas/concepts, etc.; } \\
\text { Designing/developing an object/project to be } \\
\text { used in a different situation/way other than } \\
\text { previously illustrated; } \\
\text { Raising new ideas for study/research, etc. }\end{array}$ & $\begin{array}{l}\text { I understand and can embrace the Multiple Intelligence concept. It makes sense } \\
\text { to me, knowing and studying how the brain works in the Anatomy class I teach. } \\
\text { The problem that I struggle with, as a teacher, is how to allow as much learning } \\
\text { to occur in this manner and still accomplish teaching to the standards and teach } \\
\text { the material that I need to cover. Individualized instruction, teaching through } \\
\text { these different intelligences, hands-on learning and other constructivist processes } \\
\text { are excellent opportunities for teachers to excite and have students respond. The } \\
\text { downside, and it will be that way for a long time unfortunately, is that what is } \\
\text { required by teachers and students to prove that they has been Adequate Yearly } \\
\text { Progress, is measured using the tried and true directed learning evaluation } \\
\text { instruments. For the most part, this is quicker and easier to generate numbers that } \\
\text { can be compared and compiled. I am sure that most teachers would adapt their } \\
\text { classes and use increased technology to foster theses other learning styles if the } \\
\text { bottom line of AYP was not hounding them at every turn. }\end{array}$ \\
\hline
\end{tabular}

